\title{
ANNOUNCEMENTS \\ Eleventh Annual Conference on Language Development \\ October 17, 18, and 19, 1986
}

The Boston University School of Education invites papers for the 11th Annual Conference on Language Development, to be held on October 17, 18, and 19, 1986.

Papers on the topics of first and second language acquisition, bilingualism, language disorders, writing, literacy, narratives, ASL and sign language, neurolinguistics, sociolinguistics, theoretical language acquisition, and universal grammar will be considered for presentation at the conference. The deadline for submission of abstracts is June 1, 1986. This year's keynote speaker is Noam Chomsky from the Massachusetts Institute of Technology.

For more information write: Language Development Conference, School of Education, Boston University, Boston, MA 02215.

\section{Twenty-Seventh Annual Meeting of the Psychonomic Society November 13-15, 1986}

The 27th Annual Meeting of the Psychonomic Society will be held in New Orleans, November 13-15, 1986. The meetings will begin Thursday morning and continue until Sunday noon. The headquarters hotel will be the Hyatt Regency New Orleans.

The Call for Papers is mailed to members of the Society in April; the deadline for submissions is June 27, 1986. The program and hotel reservation cards will be mailed to members in September. A copy of the program will be published in the Bulletin of the Psychonomic Society at about the same time.

For further information contact the secretary-treasurer of the Society: Judith P. Goggin, Department of Psychology, University of Texas at El Paso, El Paso, TX 79968. 